\title{
APPLICATION OF FUZZY AHP FOR RANKING AND SELECTION OF ALTERNATIVES IN CONSTRUCTION PROJECT MANAGEMENT
}

\author{
Natasa PRASCEVIC, Zivojin PRASCEVIC \\ Faculty of Civil Engineering, University of Belgrade, 11120 Belgrade, Serbia
}

Received 22 Mar 2017; accepted 18 Sep 2017

\begin{abstract}
The construction project management (CPM) is very important and large segment of entire project management (PM). Realisation of construction projects is usually long term process which requests significant financial, material, human and other resources to fulfil contracted obligations and achieve a good quality of works. Therefore, making good decisions with the satisfaction of various criteria is one of the main conditions to achieve planed business objectives and finish the project in contracted time with good quality. This paper proposes a new procedure for determination of the weights of criteria and alternatives in the Fuzzy analytic hierarchy process (FAHP) with trapezoidal fuzzy number using a new method for finding eigenvelues and eigenvectors of the criteria and alternatives, which is based on expected values of the fuzzy numbers and their products. Local and global fuzzy weights of the alternatives are determined using linear programming. In the paper a formula for ranking fuzzy numbers by reduced generalized fuzzy mean is also proposed, since ranking by the coefficient of variation is not always reliable. In the presented case study, applying proposed method, from imprecise input data are obtained enough accurate and useful results for rational ranking of alternatives related to the project realization.
\end{abstract}

Keywords: fuzzy AHP, trapezoidal fuzzy numbers, fuzzy eigenvalue, ranking alternatives, multi-criteria decision making, construction project management.

\section{Introduction}

Construction industry is completely involved in realization of construction projects serving as an engine for a development of national and global economy. In many economies this industry is well developed and competitive branch of economy. In realization of each construction project, especially large infrastructural, industrial and public projects, large number of participants is included: client (owner), contractor with subcontractors, engineer, domestic and international financial institution, producers and suppliers of materials and equipment and so on. These companies and institutions are organizationally independent and project management team has key role in their integration and orientation to achieve the clients' objectives according to previously signed contracts and their own goals.

Construction project management (CPM) encompasses, on behalf of an investor (client), the overall planning, coordination and control of a project from beginning to completion. Fundamentals of the CPM include integration, monitoring, and control of the contributors to the project, as well as the evaluation and selection of the alternatives in accomplishing the client's satisfaction (Walker 1989). Realisation of construction projects is usually long term process which requests utilization of significant financial, material, human and other resources to accomplish contracted obligations and to achieve a good quality of works. This process is very much exposed to negative influence of risk, especially in early stages.

Therefore, making good decisions with satisfaction of various criteria is one of the main conditions to achieve business objectives. All important decisions which are made in the construction project management and construction industry have multiple criteria character. The crucial decisions, which concern to the large projects, have long-term consequences on all aspects of realization and exploitation of a project. Key factors or criteria for decision making in a construction project realization are: summary costs, achieved profit, quality of executed works, duration of realization, risk during execution and exploitation, technical, functional, technological, environmental, social factors and so on. Considered alternatives of choice in decision making should fulfil requested conditions and client's objectives of the project realization. Depending on the problem for which the decision is made alternatives could be: projects for realiza-

Corresponding author: Natasa Prascevic

E-mail: natasa@grf.bg.ac.rs 
tion, contractors and subcontractors, suppliers of material and equipment, technological methods, structural systems of project buildings, strategies of maintenance of project elements and so on.

Issues that arise during realization of the project should be carefully studied at the beginning of the project realization during preparation of feasibility study. Mistakes that are made in this initial phase of realization are difficult to correct later and they could cause vast damages and financial losses. In this process it is necessary to utilise knowledge and experience of the experts and reliable data bases.

As already emphasized that decision making has multiple criteria character, important decisions should be made by applying various quantitative methods for multiple criteria decision making (MCDM). Some of them are PROMETHEE, ELECTRE, STEM, SEMPOS, TOPSIS, AHP, VIKOR and others.

Analytic hierarchy process (AHP) was proposed by Thomas Saaty $(1977,1980)$ and found wide applications in many areas. The main advantage of AHP is its possibility to be combined with other methods, including linear programming, fuzzy logic, etc. (Vaidya, Kumar 2006).

Similar to the other industrial branches, over the years, the AHP alone or combined with other methods has been used for decision making in the construction industry for solving many different problems in construction projects realisation. Besides the problems that have been emphasized in the papers of Pan (2008) and N. Prascevic and Z. Prascevic (2016), AHP can be also used for solving selection of the project management information systems, introduction of automation in the construction process, procurement selection for project realization, assessment of risk and ranking alternatives according to risk, etc.

The objective of this paper is to formulate a new procedure with trapezoidal fuzzy numbers, based on Saaty's eigenvalue approach for determination of the weights of criteria and alternatives in the fuzzy AHP for ranking and selection of alternatives in the MCDM related to problems of CPM. In this study the new procedure for determination of the principal eigenvalues and eigenvectors of fuzzy comparison matrices and requested fuzzy weights or priorities of the criteria and alternatives using linear programming is presented. Proposed procedure can be used, also, for triangular fuzzy numbers. A case study for illustration of usage of this new proposed procedure for ranking and selection alternatives in one real construction project is presented in the paper. The main purpose of the case study is to rank and after that select optimal technical, technological and economic alternative of the protection of a source and routes of pipelines for a factory of mineral water in a place in Serbia.

\section{Literature review}

The fuzzy AHP was developed by many authors and researches for solving problems of multi criteria decision making. This process uses fuzzy numbers as elements of comparison matrices and main problem is to compute the fuzzy weights as eigenvectors of these matrices. As Buckley et al. (2001) concluded, the direct approach of finding fuzzy eigenvalues and eigenvectors is computationally difficult. Foundations of the fuzzy AHP were presented by van Laarhoven and Pedrycz (1983). They applied triangular fuzzy numbers and generated elements of the priority vector by logarithmic least squares method (LLSM). The LLSM has been used by Ruoning and Xiaoyan (1992), Kwiesielewicz (1998) and other authors. Pairwise comparison values were also expressed by trapezoidal fuzzy numbers, Buckley (1985). Csutora and Buckley (2001) and Buckley et al. (2001) presented two different methods for fuzzification of Sataty's $\lambda_{\max }$ method and proposed procedures for finding fuzzy weights of the criterias and alternatives.

Many authors used the extent analysis for solving the fuzzy AHP. This method was firstly presented by Chang $(1992$, 1996). Extent analysis is used for the triangular fuzzy numbers and is based on calculation of the synthetic extent values $S_{i}$ of the pairwise comparison matrix.

Many authors combined AHP and fuzzy AHP with other methods for MCDM, such as TOPSIS and fuzzy TOPSIS (Ertugrul, Karakasoglu 2008; Kusumawardani, Agintiara 2015). Torfi et al. (2010) used the fuzzy AHP to determine the relative weights of evaluation of two levels of criteria and after that the fuzzy TOPSIS to rank the alternatives.

There are many references in the literature concerning the application of the AHP and other methods for MCDM in the construction industry and construction project management. Some of them are emphasized in the next considerations.

Antuchevičiene et al. (2010) integrated Mahalanobis distance with TOPSIS method. They used Mahalanobis distance measure to determine correlation between conflict criteria. Zavadskas et al. (2010) applied TOPSIS grey and COPRAG-S methods for risk assessment of construction projects. Salehi and Tavakkoli-Moghaddam (2008) used fuzzy TOPSIS for ranking and choice of construction projects.

Skibniewski and Chao (1992) used the AHP for evaluation of advanced construction technology. Hastak (1998) developed a decision making model (DM) and a decision support system (DSS) in construction processes. Cheung et al. (2001) developed a procurement selection method using multi attribute utility technology and the AHP. Al-Harbi (2001) applied the AHP in the project management for selection of the best contractor in a tendering procedure for the execution of construction works. Shapira and Goldenberg (2005) proposed a model based on the AHP for selection of equipment for execution of construction projects. Erdogan et al. (2017) applied AHP method for decision making in construction management. In that paper construction management problems and application of MCDM in construction management are 
Table 1. Rating scale for measuring mutual importance of criteria or alternatives

\begin{tabular}{c|c|c|c|l}
\hline \multicolumn{2}{|c|}{ Fuzzy number } & \multicolumn{2}{c}{ Reciprocal fuzzy number } & \multicolumn{1}{|c}{ Linguistic value } \\
\hline$\tilde{1}$ & $(1,1,1.5,2)$ & $\tilde{1}^{-1}$ & $(1 / 2,1 / 1.5,1,1)$ & equally significant \\
\hline$\tilde{3}$ & $(2,2.5,3.5,4)$ & $\tilde{3}^{-1}$ & $(1 / 4,1 / 3.5,1 / 2.5,1 / 2)$ & slightly significant \\
\hline$\tilde{5}$ & $(4,4.5,5.5,6)$ & $\tilde{5}^{-1}$ & $(1 / 6,1 / 5.5,1 / 4.5,1 / 4)$ & very significant \\
\hline$\tilde{7}$ & $(6,6.5,7.5,8)$ & $\tilde{7}^{-1}$ & $(1 / 8,1 / 7.5,1 . / 6.5,1 / 6)$ & greatly significant \\
\hline$\tilde{9}$ & $(8,8.5,9,9)$ & $\tilde{9}^{-1}$ & $(1 / 9,1 / 9,1 / 8.5,1 / 8)$ & absolutely significant \\
\hline$\tilde{2}, \tilde{4}, \tilde{6}, \tilde{8}$ intermediate values & $(x-1, x-0.5, x+0.5, x+1)$ & \\
\hline
\end{tabular}

focused. Also, case study with application of AHP method for selection of contractor is presented.

Mahmoodzadeh et al. (2007) used the fuzzy AHP with extent analysis and TOPSIS for selection of a project for realization. Zeng and Smith (2007) modified the fuzzy AHP and used it to obtain the priority of risk factors in construction projects. Pan (2008) proposed a model for selecting a suitable bridge construction method based on the fuzzy AHP with triangular and trapezoidal fuzzy numbers with the $\alpha$ cut concept. Jaskowski et al. (2010) proposed the extended fuzzy AHP method for assessing criteria weights for a contractor selection, according to the Polish public procurement law that is harmonized with EU guidelines on that subject. Taylan et al. (2014) used fuzzy AHP and fuzzy TOPSIS methods for construction project selection and risk assessment. N. Prascevic and Z. Prascevic (2016) considered the problem of choice of a structural system for construction an industrial hall for prescribed criteria. Polat (2016) has proposed an integrated decision approach, which use AHP and PROMETEE together for subcontractor selection problem. del Cano et al. (2016) presented method for analyzing uncertainty in the sustainable design of concrete structures. This method is based on requirement trees, value analysis and AHP.

\section{Fuzzy AHP method}

Saaty (1980) developed AHP method and based it on crisp numbers. The method consists of decomposing the problem on several levels, with the target at the highest level, criteria and subcriteria on which a decision is made at the middle levels and the alternatives at the lowest level (Saaty 1990). Since criteria and alternatives have different importance in process of decision making, for them, quadratic positive pairwise comparison matrices $F=\left[f_{i j}\right]$ are formed. These matrices are based on assessment of experts and the available data. Element $f_{i j}$ represents the ratio of weights $w_{i}$ and $w_{j}$ i.e. $f_{i j}=w_{i} / w_{j}$. Pairwise comparison matrix is reciprocal and

$$
f_{i j}=1 / f_{j i}, f_{j i}>0, f_{i i}=1, i, j=1,2, \ldots n .
$$

If elements of this reciprocal matrix satisfy following conditions:

$f_{i j}=f_{i k} f_{k j} \quad$ or $\quad f_{j k}=f_{i k} / f_{i j}, \quad i, j, k=1,2, \ldots, n$,

this matrix is called the consistent matrix.

Since the judgments of comparison values are usually expressed linguistically or cannot be precisely measured or calculated, a better and more realistic way is to express these comparison values by fuzzy numbers and perform the fuzzy Analytical hierarchical process (fuzzy AHP).

During formulation of mathematical model for many problems in the practice, the triangular and trapezoidal fuzzy numbers, due to their simplicity, are commonly utilized. In this paper trapezoidal fuzzy numbers are used. In Table 1 rating scale for measuring comparison values and corresponding trapezoidal fuzzy numbers are presented. Presented rating scale is obtained by fuzzification of Saaty's fundamental rating scale (Saaty 1977). Membership functions for trapezoidal fuzzy numbers are presented in Figure 1.

\subsection{Proposed fuzzy AHP procedure for trapezoidal fuzzy numbers}

Fuzzy AHP procedure is presented in Figure 2.

Fuzzy AHP procedure starts with definition of overall goal and hierarchical structure which consists of criteria and sub criteria, if necessary, and alternatives.

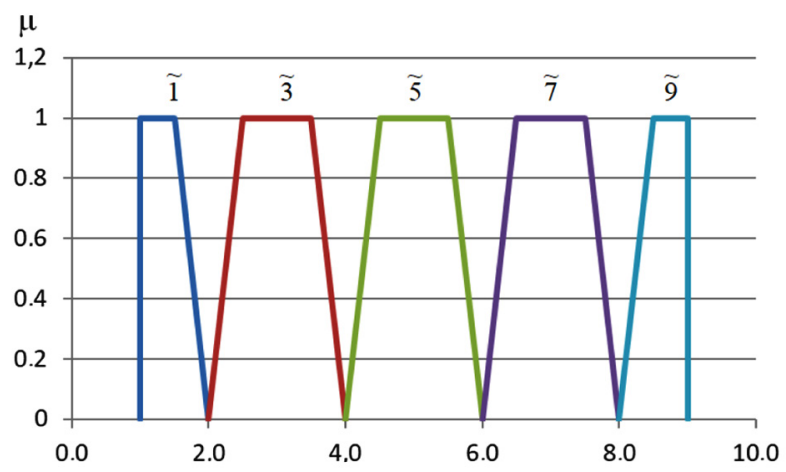

Fig. 1. Membership functions for trapezoidal fuzzy numbers 


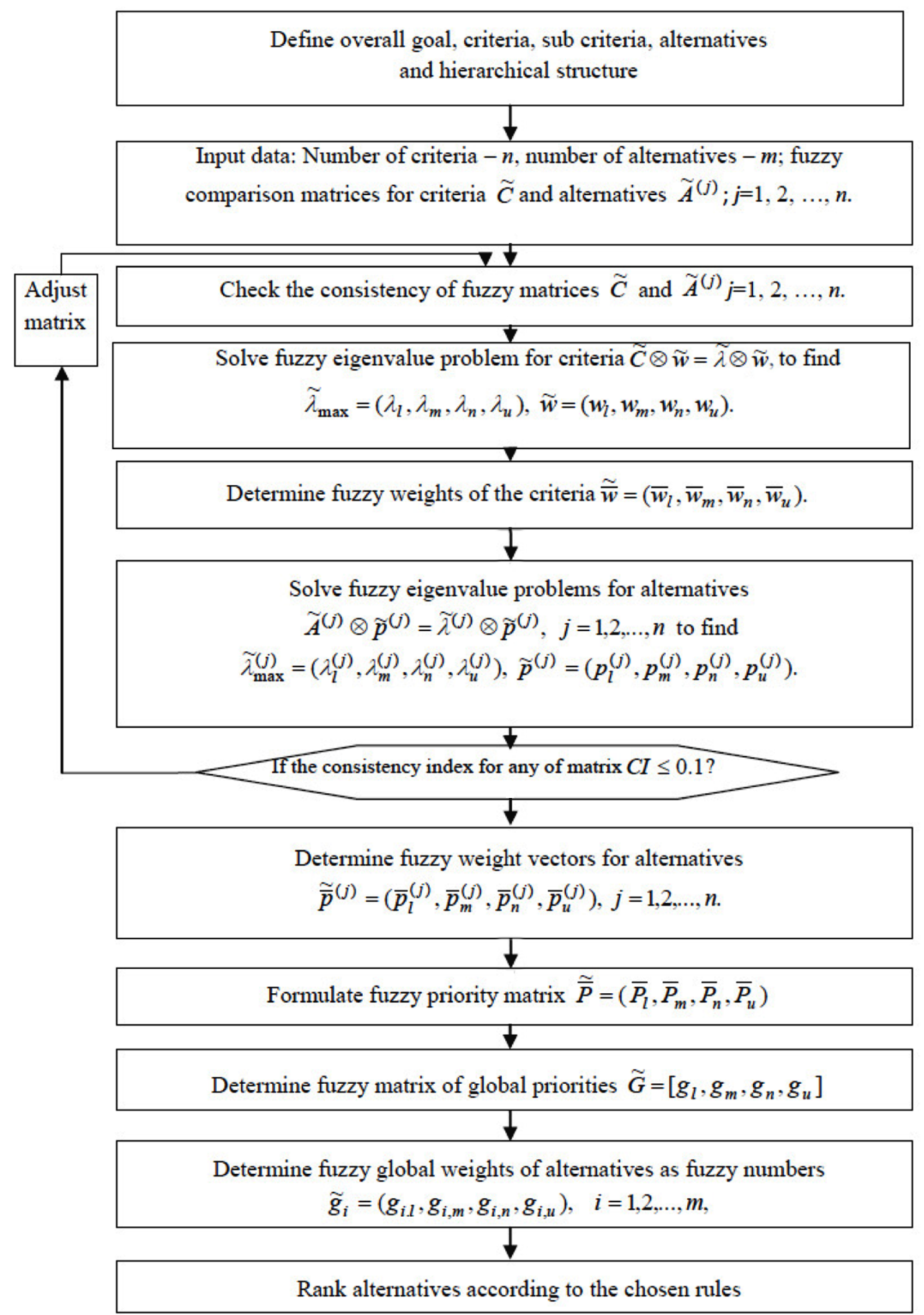

Fig. 2. Fuzzy AHP procedure

After that, pairwise comparison reciprocal fuzzy matrix $\widetilde{C}$ for the criteria $C_{1}, C_{2}, \ldots, C_{n}$ is formulated. Elements of this matrix are assessed priority values presented by trapezoidal fuzzy numbers $\tilde{c}_{i j}=\left(c_{i j, l}, c_{i j, m}, c_{i j, n}, c_{i j, u}\right)$ $(i, j=1,2, \ldots, n)$ using appropriate comparison scale. At the similar way pairwise comparison matrices for the alternatives $\widetilde{A}^{(j)}$ related to the criteria $C_{j}(j=1,2, \ldots, n)$ are formulated (Eqn (3)):

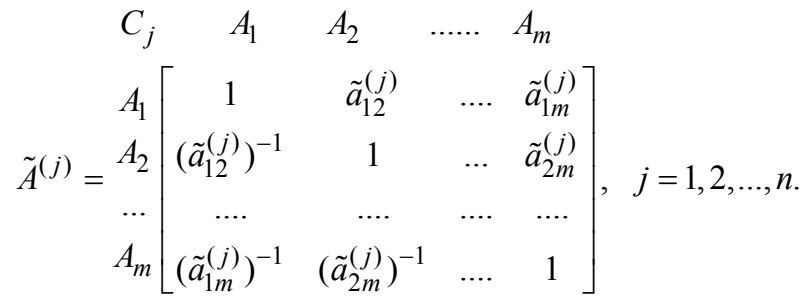


In the next step the principal fuzzy eigenvalue $\tilde{\lambda}_{\max }=\left(\lambda_{l}, \lambda_{m}, \lambda_{n}, \lambda_{u}\right)$ and the corresponding fuzzy eigenvectors $\widetilde{w}=\left(w_{l}, w_{m}, w_{n}, w_{u}\right)$ are obtained by solving the fuzzy eigenvalue problem:

$$
\widetilde{C} \otimes \widetilde{w}=\tilde{\lambda} \otimes \widetilde{w}
$$

or

$$
\tilde{c}_{i 1} \otimes \tilde{w}_{1} \oplus \tilde{c}_{i 2} \otimes \tilde{w}_{2} \oplus \ldots \oplus \tilde{c}_{i n} \otimes \tilde{w}_{n}=\tilde{\lambda} \otimes \tilde{w}_{i}, i=1,2, \ldots, n .
$$

In this paper we present solution of this eigenvalue problem based on the calculation of expected values of the fuzzy trapezoidal numbers and their products.

Expected value for Eqn (5), according to (A2) is:

$$
\begin{aligned}
& E V \sum_{j=1}^{n}\left(\tilde{c}_{i j} \otimes \tilde{w}_{j}\right)= \\
& \frac{1}{12} \sum_{j=1}^{n}\left[2\left(c_{i j, l}+c_{i j, m}\right) w_{j, l}+\left(c_{i j, l}+2 c_{i j, m}\right) w_{j, m}+\right. \\
& \left.\quad\left(2 c_{i j, n}+c_{i j, u}\right) w_{j, n}+\left(c_{i j, n}+2 c_{i j, u}\right) w_{j, u}\right],
\end{aligned}
$$

$$
\begin{aligned}
& E V\left(\tilde{\lambda} \otimes \tilde{w}_{i}\right)= \\
& \frac{1}{12}\left[\left(2 \lambda_{l}+\lambda_{m}\right) w_{i, l}+\left(\lambda_{l}+2 \lambda_{m}\right) w_{i, m}+\right. \\
& \left.\quad\left(2 \lambda_{n}+\lambda_{u}\right) w_{i, n}+\left(\lambda_{n}+2 \lambda_{u}\right) w_{i, u}\right] \quad i, j=1,2, \ldots, n .
\end{aligned}
$$

Introducing Eqn (6) in Eqn (5) is obtained:

$$
\begin{aligned}
& \bar{C}_{l} w_{l}+\bar{C}_{m} w_{m}+\bar{C}_{n} w_{n}+\bar{C}_{u} w_{u}= \\
& \bar{\lambda}_{l} w_{l}+\bar{\lambda}_{m} w_{m}+\bar{\lambda}_{n} w_{n}+\bar{\lambda}_{u} w_{u},
\end{aligned}
$$

where

$$
\begin{array}{cl}
\bar{C}_{l}=2 C_{l}+C_{m}, & \bar{C}_{m}=C_{l}+2 C_{m}, \\
\bar{C}_{n}=2 C_{n}+C_{u}, & \bar{C}_{u}=C_{m}+2 C_{u} . \\
\bar{\lambda}_{l}=2 \lambda_{l}+\lambda_{m}, & \bar{\lambda}_{m}=\lambda_{l}+2 \lambda_{m}, \\
\bar{\lambda}_{n}=2 \lambda_{n}+\lambda_{u}, & \bar{\lambda}_{u}=\lambda_{m}+2 \lambda_{u} . \\
w_{l}^{T}=\left[w_{1, l}, w_{2, l}, \ldots, w_{n, l}\right], & w_{m}^{T}=\left[w_{1, m}, w_{2, m}, \ldots, w_{n, m}\right], \\
w_{n}^{T}=\left[w_{1, n}, w_{2, n}, \ldots, w_{n, n}\right] . & w_{u}^{T}=\left[w_{1, u}, w_{2, u}, \ldots, w_{n, u}\right] .
\end{array}
$$

In the Eqn (8) $C_{l}, C_{m}, C_{n}$ and $C_{u}$ are characteristic crisp matrices given by the next expressions:

$$
C_{l}=\left[\begin{array}{cccc}
1 & c_{12, l} & \ldots & c_{1 k, l} \\
c_{12, u}^{-1} & 1 & \ldots & c_{2 k, l} \\
\ldots & \ldots & \ldots & \ldots \\
c_{1 k, u}^{-1} & c_{2 k, u}^{-1} & \ldots & 1
\end{array}\right],
$$

$$
C_{m}=\left[\begin{array}{cccc}
1 & c_{12, m} & \ldots & c_{1 k, m} \\
c_{12, n}^{-1} & 1 & \ldots & c_{2 k, m} \\
\ldots & \ldots & \ldots & \ldots \\
c_{1 k, n}^{-1} & c_{2 k, n}^{-1} & \ldots & 1
\end{array}\right]
$$

$$
C_{n}=\left[\begin{array}{cccc}
1 & c_{12, n} & \ldots & c_{1 k, n} \\
c_{12, m}^{-1} & 1 & \ldots & c_{2 k, n} \\
\ldots & \ldots & \ldots & \ldots \\
c_{1 k, m}^{-1} & c_{2 k, m}^{-1} & \ldots & 1
\end{array}\right]
$$

$$
C_{u}=\left[\begin{array}{cccc}
1 & c_{12, u} & \ldots & c_{1 k, u} \\
c_{12, l}^{-1} & 1 & \ldots & c_{2 k, u} \\
\cdot & \cdot & \ldots & \cdot \\
c_{1 k, l}^{-1} & c_{2 k, l}^{-1} & \ldots & 1
\end{array}\right]
$$

Since all matrices, eigenvalues and eigenvectors are positive, the system of linear Eqn (7) can be decomposed in four systems of crisp linear homogenous systems. In such a way, the fuzzy eigenvalue problem (4) is exchanged with four crisp eigenvalue problems.

$$
\begin{aligned}
& \bar{C}_{l} w_{l}=\bar{\lambda}_{l} w_{l}, \quad \bar{C}_{m} w_{m}=\bar{\lambda}_{m} w_{m}, \\
& \bar{C}_{n} w_{n}=\bar{\lambda}_{n} w_{n}, \quad \bar{C}_{u} w_{u}=\bar{\lambda}_{u} w_{u} .
\end{aligned}
$$

Solving these four eigenvalue problems, are obtained eigenvectors $w_{l}, w_{m}, w_{n}$ and $w_{u}$ and auxiliary eigenvalues $\bar{\lambda}_{l}, \bar{\lambda}_{m}, \bar{\lambda}_{n}$ and $\bar{\lambda}_{u}$. After solving the system (9) principal eigenvalues $\tilde{\lambda}_{\text {max }}=\left(\lambda_{l}, \lambda_{m}, \lambda_{n}, \lambda_{u}\right)$ are determined.

Since fuzzy matrix $\widetilde{C}$ need to satisfy consistency condition, before next step, consistency index $C I$ and consistency ratio $C R$ are calculated according to Saaty (1980):

$$
C I=\left(\lambda_{\max }-n\right) /(n-1), C R=C I / R I .
$$

where $\lambda_{\max }$ is the maximum eigenvalue of crisp matrix $C_{c}=\left(C_{m}+C_{n}\right) / 2$ (Buckley 1985) and $R I$ is random consistency given by Saaty (1980). The fuzzy matrix $\widetilde{C}$ is considered consistent if $C R \leq 0.10$, otherwise fuzzy matrix $\widetilde{C}$ should be changed by changing those elements leading to inconsistency. Since consistency ratio $C R$ depends on $\lambda_{\max }$ and $\lambda_{\max } \leq \max _{i} \sum_{j=1}^{n} C_{j}$ (Saaty 1977), it means that in the row of matrix $C_{c}$ with maximum sum of the elements values of the elements should be reduced.

In the next step, in order to satisfy the conditions that for principal eigenvalues $\lambda_{l}<\lambda_{m}<\lambda_{n}<\lambda_{u}$ corresponding eigenvectors $\bar{w}_{l}, \bar{w}_{m}, \bar{w}_{n}, \bar{w}_{u}$, which represent fuzzy weights, must satisfy next requirements $\bar{w}_{l} \leq \bar{w}_{m} \leq \bar{w}_{n}, \leq \bar{w}_{u}$. In this paper linear programming is used to find requested weights that satisfy these conditions. 
For the trapezoidal fuzzy number, requested fuzzy weights $\bar{w}_{l}, \bar{w}_{m}, \bar{w}_{n}$ and $\bar{w}_{u}$ may be expressed by the known eigenvectors $w_{l}, w_{m}, w_{n}$ and $w_{u}$ :

$$
\bar{w}_{l}=y_{l} w_{l}, \quad \bar{w}_{m}=y_{m} w_{m}, \bar{w}_{n}=y_{n} w_{n}, \bar{w}_{u}=y_{u} w_{u},
$$

where $y_{l}, y_{m}, y_{n}$ and $y_{u}$ are unknown variables.

Introducing vector

$$
w_{r}=\left(w_{m}+w_{n}\right) / 2,
$$

next constraints are valid $\bar{w}_{l} \leq w_{r}, \bar{w}_{m} \leq w_{r}, \bar{w}_{n} \geq w_{r}$, $\bar{w}_{u} \geq w_{r}$.

These constraints can be written according to Eqn (14) as:

$$
\begin{gathered}
y_{l} w_{l} \leq w_{r}, \quad y_{m} w_{m} \leq w_{r}, \\
-y_{n} w_{n} \leq-w_{r}, \quad-y_{u} w_{u} \leq-w_{r}, \\
y_{l} w_{l}-y_{m} w_{m} \leq 0, \quad y_{n} w_{n}-y_{u} w_{u} \leq 0 .
\end{gathered}
$$

The fuzziness, which depends upon unknowns $y_{l}, y_{m}, y_{n}$ and $y_{u}$, should be minimized, so that the objective function of this problem is:

$$
z=\min \left(-y_{l}-y_{m}+y_{n}+y_{u}\right) .
$$

Solving linear program (16) and (17) for the trapezoidal fuzzy numbers unknowns $y_{l}, y_{m}, y_{n}$ and $y_{u}$ are obtained. Finally, according to Eqn (14), the requested weight vectors $\bar{w}_{l}, \bar{w}_{m}, \bar{w}_{n}$ and $\bar{w}_{u}$ are determined.

In the next step, by using previously explained procedure, fuzzy eigenvalue problems:

$$
\widetilde{A}^{(j)} \otimes \widetilde{p}^{(j)}=\tilde{\lambda}^{(j)} \otimes \widetilde{p}^{(j)}, j=1,2, \ldots, n
$$

are solved and fuzzy principal eigenvalues $\tilde{\lambda}_{\max }^{(j)}=$ $\left(\lambda_{l}^{(j)}, \lambda_{m}^{(j)}, \lambda_{n}^{(j)}, \lambda_{u}^{(j)}\right)$, fuzzy eigenvectors $\tilde{p}^{(j)}=$ $\left(p_{l}^{(j)}, p_{m}^{(j)}, p_{n}^{(j)}, p_{u}^{(j)}\right)$ are determined.

Using proposed method based on linear programming, fuzzy priority vectors (weights) $\tilde{\bar{p}}^{(j)}=$ $\left(\bar{p}_{l}^{(j)}, \bar{p}_{m}^{(j)}, \bar{p}_{n}^{(j)}, \bar{p}_{u}^{(j)}\right)(j=1,2, . ., n)$ are determined.

Global priorities vectors of the alternatives $A_{i}(i=1,2, \ldots, m)$ are calculated as:

$$
\begin{aligned}
& g_{l}=\bar{P}_{l} \bar{w}_{l}=\left[\begin{array}{c}
g_{1, l} \\
g_{2, l} \\
\vdots \\
g_{m . l}
\end{array}\right] \quad g_{m}=\bar{P}_{m} \bar{w}_{m}=\left[\begin{array}{c}
g_{1, m} \\
g_{2, m} \\
\vdots \\
g_{m \cdot m}
\end{array}\right] \\
& g_{n}=\bar{P}_{n} \bar{w}_{n}=\left[\begin{array}{c}
g_{1, n} \\
g_{2, n} \\
\vdots \\
g_{m . n}
\end{array}\right] \quad g_{u}=\bar{P}_{u} \bar{w}_{u}=\left[\begin{array}{c}
g_{1, u} \\
g_{2, u} \\
\vdots \\
g_{m . u}
\end{array}\right]
\end{aligned}
$$

where

$$
\begin{aligned}
& \bar{P}_{l}=\left[\begin{array}{lllll}
\bar{p}_{l}^{(1)} & \bar{p}_{l}^{(2)} & \ldots & \bar{p}_{l}^{(n)}
\end{array}\right], \quad \bar{P}_{m}=\left[\begin{array}{llll}
\bar{p}_{m}^{(1)} & \bar{p}_{m}^{(2)} & \ldots & \bar{p}_{m}^{(n)}
\end{array}\right], \\
& \bar{P}_{n}=\left[\begin{array}{llll}
\bar{p}_{n}^{(1)} & \bar{p}_{n}^{(2)} & \ldots & \bar{p}_{n}^{(n)}
\end{array}\right], \quad \bar{P}_{u}=\left[\begin{array}{lllll}
\bar{p}_{u}^{(1)} & \bar{p}_{u}^{(2)} & \ldots & \bar{p}_{u}^{(n)}
\end{array}\right] . \\
& \bar{w}_{l}=\left[\begin{array}{c}
\bar{w}_{1, l} \\
\bar{w}_{2, l} \\
\vdots \\
\bar{w}_{n, l}
\end{array}\right], \bar{w}_{m}=\left[\begin{array}{c}
\bar{w}_{1, m} \\
\bar{w}_{2, m} \\
\vdots \\
\bar{w}_{n, m}
\end{array}\right], \bar{w}_{n}=\left[\begin{array}{c}
\bar{w}_{1, n} \\
\bar{w}_{2, n} \\
\vdots \\
\bar{w}_{n, n}
\end{array}\right], \bar{w}_{u}=\left[\begin{array}{c}
\bar{w}_{1, u} \\
\bar{w}_{2, u} \\
\vdots \\
\bar{w}_{n, u}
\end{array}\right] .
\end{aligned}
$$

The fuzzy matrix of global priorities for the alternatives $A_{1}, A_{2}, \ldots, A_{m}$ is $\widetilde{G}=\left[g_{l} g_{m} g_{n} g_{u}\right]$.

Row $i(I=1,2, \ldots, m)$ of matrix $\widetilde{G}$ represents weight of alternative $A_{i}$ as trapezoidal fuzzy number $\tilde{g}_{i}=\left(g_{i, l}, g_{i, m}, g_{i, n}, g_{i, u}\right)$.

\subsection{Ranking of alternatives}

Last step of AHP procedure is ranking of alternatives according to these fuzzy numbers. Fuzzy numbers can be ranked according to many proposals. In this paper are used: generalized mean and standard deviation (Lee, Li 1988), generalized coefficient of variation (Cheng 1998), distance to the centroid point and the reduced mean.

Generalized mean $g_{i, e}$ and standard deviation of the trapezoidal fuzzy number $\tilde{g}_{i}=\left(g_{i, l}, g_{i, m}, g_{i, n}, g_{i, u}\right)$ are calculated according to the probability measure of this number as a fuzzy event, which was introduced by Zadeh (1968) (see Appendix 1). For the uniform distribution of probability of the trapezoidal fuzzy number generalized expected value $g_{i, e}$, standard deviation $\sigma_{i}$ and coefficient of variation $C V_{i}$ are according to Cheng (1998):

$$
g_{i, e}=\frac{g_{i, u}^{2}+g_{i, n} g_{i, u}+g_{i, n}^{2}-g_{i, l}^{2}-g_{i, l} g_{i, m}-g_{i, m}^{2}}{3\left(g_{i, u}-g_{i, l}+g_{i, n}-g_{i, m}\right)} ;
$$

$$
\begin{aligned}
& \sigma_{i}= \\
& {\left[\frac{g_{i, u}\left(g_{i, u}^{2}+g_{i, u} g_{i, n}+g_{i, n}^{2}\right)+g_{i, n}^{3}-g_{i, m}^{3}-g_{i, l}\left(g_{i, l}^{2}+g_{i, l} g_{i, m}+g_{i, m}^{2}\right)}{6\left(g_{i, u}-g_{i, l}+g_{i, n}-g_{i, m}\right)}\right.} \\
& \left.-\left(g_{i, e}^{U}\right)^{2}\right]^{1 / 2} ;
\end{aligned}
$$

$$
C V_{i}=\sigma_{i} / g_{i, e}, \quad i=1,2, \ldots, m .
$$

The fuzzy number with higher generalized mean and lower generalized standard deviation (spread) is better ranked (Lee, Li 1988). Cheng (1998) has criticized this method for ranking fuzzy numbers and concluded that the generalized standard deviation and mean value cannot be a sole basis for comparing two fuzzy numbers. He proposed to rank fuzzy numbers according to the generalized 
coefficient of variation $C V_{i}$ defined by Eqn (24). The fuzzy number with smaller $C V_{i}$ is better ranked. But, this is not always reliable method, especially in the cases of fuzzy numbers with different generalized expected values when values of these coefficients are mutually very close. In that case the fuzzy number with higher expected value $g_{i, e}$, calculated by expressions (30) should be ranked higher.

In the same paper Cheng (1998) proposed ranking fuzzy numbers by distance from original point $O\left(g_{i}=0, \mu=0\right)$ to the centroid point of a fuzzy number $C\left(g_{i}=x_{c}, \mu=y_{c}\right)$.

For the trapezoidal number $\tilde{g}_{i}$ coordinates of the centroid points are:

$$
g_{i, c}=g_{i, e} ; \quad y_{c}=\frac{g_{i, u}+2\left(g_{i, n}-\mathrm{g}_{i, m}\right)-g_{i, l}}{3\left(g_{i, u}-\mathrm{g}_{i, l}+g_{i, n}-\mathrm{g}_{i, m}\right)} .
$$

The ranking function $R(\tilde{A})$ is the distance from the original point to the centroid point:

$$
R(\widetilde{g})=\sqrt{g_{i, c}^{2}+y_{c}^{2}} .
$$

The fuzzy number $\tilde{A}$ with bigger value $R(\tilde{A})$ is higher ranked.

In this paper formula for ranking fuzzy numbers with reduced generalized mean value of a fuzzy number is proposed:

$$
g_{e r}=g_{i, e}-\beta \sigma_{i}, \quad i=1,2, \ldots, m, \beta=0.75 \text { to } 1.25 \text {, }
$$

where $\beta$ is a coefficient of influence of the spread $\sigma_{i}$ on the rank of the considered fuzzy number.

\section{Case study}

This section presents ranking and selection of best technical, technological and economic variant (alternative) of a project realized by a company in Serbia. As illustration of application of fuzzy AHP methodology project of protection of a source and routes of pipelines for a factory of mineral water is considered. According to the technical and technological requirements, given in the project documentation, the experts from this company, have formulated the problem, proposed overall goal, nine criteria $C_{1}, C_{2}, \ldots, C_{9}$ for alternatives ranking and four alternatives $A_{1}, A_{2}, A_{3}, A_{4}$. Each alternative includes realization of the projects, protection and maintenance of the system. The criteria are: investments $\left(C_{1}\right)$, the cost of exploitation $\left(C_{2}\right)$, safety in the operation of facilities $\left(C_{3}\right)$, duration of construction $\left(C_{4}\right)$, the influence of environment on future facilities $\left(C_{5}\right)$, the impact of the planned facilities on the environment $\left(C_{6}\right)$, the influence of sociological factors on the planned facilities $\left(C_{7}\right)$, the impact of sociopolitical community on the planned facilities $\left(C_{8}\right)$, visual and aesthetic effects $\left(C_{9}\right)$. Hierarchy structure is shown in Figure 3.

Works on the project of protection of a source and routes of pipelines for a factory of mineral water are divided into two groups: compulsory works, foreseen in all alternatives and additional works, foreseen for alternatives 3 and 4 . Alternative 1 implies an increase in the legal minimum of safety in the functioning of the facility, the great impact of future facilities on the source, pipeline and the environment, as well as the insignificant influence of socially political factors and communities on the projected facilities. In the case of alternative 2, the legal minimum of safety in the functioning of the facility is also required, but also the increased impact of future facilities on the source, pipeline and the environment, as well as the average impact of the social political community on the projected facilities. Alternatives 3 and 4 foresee additional work as they require medium (alternative 3 ) or high (alternative 4) degree of safety in the functioning of the facility. Alternatives 3 and 4 have the medium or minimal impact of future facilities on the source, pipeline and the environment, as well as the increased or highest impact of socially political factors and community on the

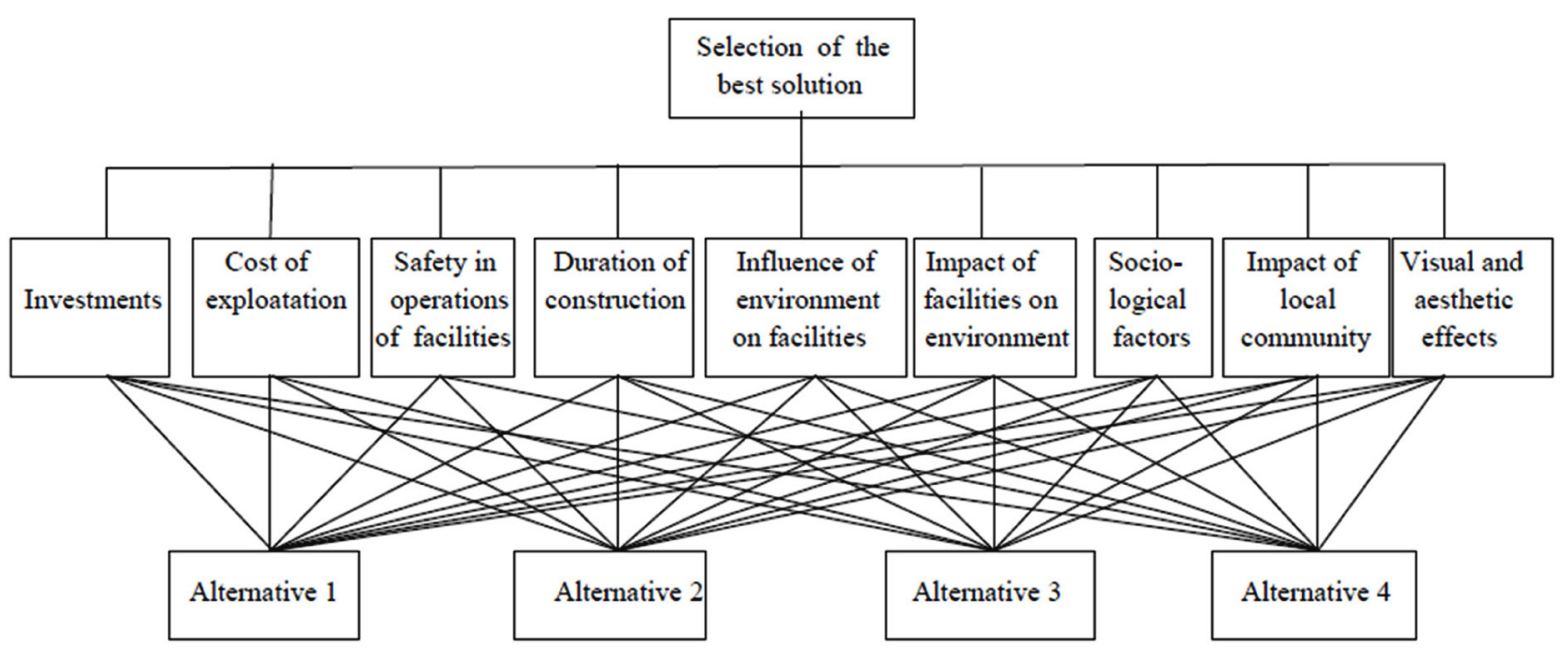

Fig. 3. Hierarchy structure of the case study 
designed facilities. According to the value of investments, the alternatives are sorted $A_{1}, A_{2}, A_{3}, A_{4}$, with the least investment in alternative 1 and the highest in alternative 4.

Alternatives 3 and 4 provide the highest level of system security and require higher quality of performance and installation of equipment compared to alternatives 1 and 2 . Therefore, the investment value for alternatives 3 and 4 is higher than for alternatives 1 and 2. Costs of maintaining a future system for alternatives 3 and 4 are also lower. These are the basic reasons why experts ranked alternatives 3 and 4 better than alternatives 1 and 2 .

The decision-making team, i.e. the team for the estimating values of criteria functions for alternatives, consisted of five experts who participated in design of the project. The head of the team was a project manager. On the basis of technical documentation, plans for project realization and the other relevant data, they determined, by a consensus, the values of the mentioned criteria functions for the given alternatives and preliminarily assessed the weight of the criteria as crisp numbers. Based on these data, the authors of the paper formulated the appropriate fuzzy comparison matrices by calculating the ratios of value that are have being compared. According to these obtained ratios, pairwise comparison matrices of criteria and alternatives are defined using Table 1, as follows:

$$
\tilde{C}=\left[\begin{array}{ccccccccc}
1 & \tilde{1}^{-1} & \tilde{3}^{-1} & \tilde{3}^{-1} & \tilde{1}^{-1} & \tilde{3} & \tilde{2} & \tilde{2} & \tilde{2} \\
\tilde{1} & 1 & \tilde{3}^{-1} & \tilde{3}^{-1} & \tilde{1}^{-1} & \tilde{3} & \tilde{2} & \tilde{2} & \tilde{2} \\
\tilde{3} & \tilde{3} & 1 & \tilde{1}^{-1} & \tilde{3} & \tilde{6} & \tilde{5} & \tilde{4} & \tilde{5} \\
\tilde{3} & \tilde{3} & \tilde{1} & 1 & \tilde{3} & \tilde{6} & \tilde{5} & \tilde{4} & \tilde{5} \\
\tilde{1} & \tilde{1} & \tilde{3}^{-1} & \tilde{3}^{-1} & 1 & \tilde{3} & \tilde{2} & \tilde{2} & \tilde{2} \\
\tilde{3}^{-1} & \tilde{3}^{-1} & \tilde{6}^{-1} & \tilde{6}^{-1} & \tilde{3}^{-1} & 1 & \tilde{1}^{-1} & \tilde{2}^{-1} & \tilde{1}^{-1} \\
\tilde{2}^{-1} & \tilde{2}^{-1} & \tilde{5}^{-1} & \tilde{5}^{-1} & \tilde{2}^{-1} & \tilde{1} & 1 & \tilde{1}^{-1} & \tilde{1}^{-1} \\
\tilde{2}^{-1} & \tilde{2}^{-1} & \tilde{4}^{-1} & \tilde{4}^{-1} & \tilde{2}^{-1} & \tilde{2} & \tilde{1} & 1 & \tilde{1} \\
\tilde{2}^{-1} & \tilde{2}^{2} & \tilde{5}^{-1} & \tilde{5}^{-1} & \tilde{2}^{-1} & \tilde{1} & \tilde{1} & \tilde{1}^{-1} & 1
\end{array}\right]
$$

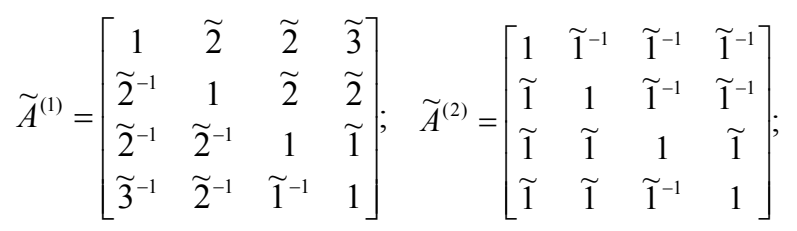

$$
\widetilde{A}^{(3)}=\left[\begin{array}{cccc}
1 & \tilde{1}^{-1} & \widetilde{2}^{-1} & \widetilde{3}^{-1} \\
\widetilde{1} & 1 & \widetilde{2}^{-1} & \widetilde{3}^{-1} \\
\widetilde{2} & \widetilde{2} & 1 & \widetilde{2}^{-1} \\
\widetilde{3} & \widetilde{3} & \widetilde{2} & 1
\end{array}\right] ; \quad \widetilde{A}^{(4)}=\left[\begin{array}{cccc}
1 & \widetilde{1}^{-1} & \widetilde{2}^{-1} & \widetilde{2}^{-1} \\
\widetilde{1} & 1 & \widetilde{2}^{-1} & \widetilde{1}^{-1} \\
\widetilde{2} & \widetilde{2} & 1 & \widetilde{1}^{-1} \\
\widetilde{2} & \widetilde{1} & \widetilde{1} & 1
\end{array}\right] ;
$$

$$
\widetilde{A}^{(5)}=\left[\begin{array}{cccc}
1 & \widetilde{3}^{-1} & \widetilde{4}^{-1} & \widetilde{5}^{-1} \\
\widetilde{3} & 1 & \widetilde{1}^{-1} & \widetilde{2}^{-1} \\
\widetilde{4} & \widetilde{1} & 1 & \widetilde{1}^{-1} \\
\widetilde{5} & \widetilde{2} & \widetilde{1} & 1
\end{array}\right] ; \quad \widetilde{A}^{(6)}=\left[\begin{array}{cccc}
1 & \widetilde{3}^{-1} & \widetilde{4}^{-1} & \widetilde{5}^{-1} \\
\widetilde{3} & 1 & \tilde{1}^{-1} & \widetilde{2}^{-1} \\
\widetilde{4} & \widetilde{1} & 1 & \widetilde{1}^{-1} \\
\widetilde{5} & \widetilde{2} & \widetilde{1} & 1
\end{array}\right]
$$

$$
\begin{aligned}
& \widetilde{A}^{(7)}=\left[\begin{array}{cccc}
1 & \tilde{1} & \widetilde{5} & \widetilde{5} \\
\tilde{1}^{-1} & 1 & \widetilde{4} & \widetilde{4} \\
\widetilde{4}^{-1} & \widetilde{4}^{-1} & 1 & \widetilde{1}^{-1} \\
\widetilde{5}^{-1} & \widetilde{4}^{-1} & \widetilde{1} & 1
\end{array}\right] ; \quad \widetilde{A}^{(8)}=\left[\begin{array}{cccc}
1 & \widetilde{1} & \tilde{2} & \widetilde{5} \\
\tilde{1}^{-1} & 1 & \widetilde{1} & \widetilde{4} \\
\widetilde{2}^{-1} & \widetilde{1}^{-1} & 1 & \widetilde{3} \\
\widetilde{5}^{-1} & \widetilde{4}^{-1} & \widetilde{3}^{-1} & 1
\end{array}\right] ; \\
& \widetilde{A}^{(9)}=\left[\begin{array}{cccc}
1 & \widetilde{1}^{-1} & \widetilde{4}^{-1} & \widetilde{5}^{-1} \\
\widetilde{1} & 1 & \widetilde{3}^{-1} & \widetilde{4}^{-1} \\
\widetilde{4} & \widetilde{3} & 1 & \widetilde{1}^{-1} \\
\widetilde{5} & \widetilde{4} & \widetilde{1} & 1
\end{array}\right] .
\end{aligned}
$$

For the fuzzy input matrix of criteria $\widetilde{C}$, according to Eqn (11), are formed crisp matrices $C_{l}, C_{m}$, $C_{n}$ and $C_{u}$. After applying proposed procedure are found principal eigenvalues of the problem (4) $\tilde{\lambda}_{\max }=(6.630,7.393,10.727,12.840)$ and corresponding eigenvectors that presents fuzzy weights for criteria $\widetilde{\bar{w}}=\left(\bar{w}_{l}, \bar{w}_{m}, \bar{w}_{n}, \bar{w}_{u}\right)$ (Table 2).

Table 2. Fuzzy weights for criteria

\begin{tabular}{crrrc}
\hline Criteria $i$ & $\bar{w}_{l}$ & $\bar{w}_{m}$ & $\bar{w}_{n}$ & $\bar{w}_{u}$ \\
\hline$C_{1}$ & 0.078 & 0.083 & 0.099 & 0.101 \\
$C_{2}$ & 0.083 & 0.087 & 0.105 & 0.108 \\
$C_{3}$ & 0.237 & 0.248 & 0.248 & 0.248 \\
$C_{4}$ & 0.253 & 0.262 & 0.262 & 0.265 \\
$C_{5}$ & 0.089 & 0.092 & 0.111 & 0.115 \\
$C_{6}$ & 0.340 & 0.034 & 0.037 & 0.038 \\
$C_{7}$ & 0.043 & 0.044 & 0.052 & 0.055 \\
$C_{8}$ & 0.053 & 0.053 & 0.065 & 0.069 \\
$C_{9}$ & 0.046 & 0.046 & 0.055 & 0.058 \\
\hline
\end{tabular}

At the third level, for the input pairwise comparison matrices of the alternatives $\tilde{A}^{(j)}$ related to the criteria $C_{j}(j=1,2,3, \ldots, 9)$ are calculated principal eigenvalues $\tilde{\lambda}_{\max }^{(j)}=\left(\lambda_{l}^{(j)}, \lambda_{m}^{(j)}, \lambda_{n}^{(j)}, \lambda_{u}^{(j)}\right)$ (presented in Table 3 ) and corresponding local priority (weight) vectors $\tilde{\bar{p}}^{(j)}=\left(\bar{p}_{l}^{(j)}, \bar{p}_{m}^{(j)}, \bar{p}_{n}^{(j)}, \bar{p}_{u}^{(j)}\right)$.

Table 3. Eigenvalues for comparison matrices $A^{(j)}$

\begin{tabular}{ccccc}
\hline$\tilde{A}^{(j)}$ & $\bar{w}_{l}$ & $\bar{w}_{m}$ & $\bar{w}_{n}$ & $\bar{w}_{u}$ \\
\hline$\tilde{A}^{(1)}$ & 2.887 & 3.258 & 4.839 & 5.939 \\
\hline$\tilde{A}^{(2)}$ & 3.147 & 3.462 & 4.695 & 5.292 \\
\hline$\tilde{A}^{(3)}$ & 2.947 & 3.218 & 4.751 & 5.755 \\
\hline$\tilde{A}^{(4)}$ & 3.008 & 3.359 & 4.758 & 5.595 \\
\hline$\tilde{A}^{(5)}$ & 3.151 & 3.428 & 4.591 & 5.258 \\
\hline$\tilde{A}^{(6)}$ & 3.151 & 3.428 & 4.591 & 5.258 \\
\hline$\tilde{A}^{(7)}$ & 3.313 & 3.525 & 4.472 & 4.954 \\
\hline$\tilde{A}^{(8)}$ & 3.151 & 3.428 & 4.591 & 5.258 \\
\hline$\tilde{A}^{(9)}$ & 3.248 & 3.458 & 4.507 & 5.030 \\
\hline
\end{tabular}


Priority fuzzy matrices $\bar{P}_{l}, \bar{P}_{m}, \bar{P}_{n}$ and $\bar{P}_{u}$, that contain local priority vectors according to Eqn (20) are:

$$
\begin{aligned}
& \bar{P}_{l}=\left[\begin{array}{llllllllll}
0.379 & 0.191 & 0.127 & 0.149 & 0.075 & 0.075 & 0.448 & 0.372 & 0.085 \\
0.238 & 0.221 & 0.148 & 0.222 & 0.199 & 0.199 & 0.338 & 0.287 & 0.109 \\
0.168 & 0.296 & 0.224 & 0.268 & 0.287 & 0.287 & 0.082 & 0.199 & 0.322 \\
0.133 & 0.256 & 0.416 & 0.312 & 0.372 & 0.372 & 0.094 & 0.075 & 0.438
\end{array}\right] ; \\
& \bar{P}_{m}=\left[\begin{array}{lllllllll}
0.413 & 0.205 & 0.130 & 0.149 & 0.075 & 0.075 & 0.457 & 0.386 & 0.087 \\
0.255 & 0.232 & 0.148 & 0.226 & 0.208 & 0.208 & 0.354 & 0.298 & 0.109 \\
0.168 & 0.296 & 0.240 & 0.275 & 0.298 & 0.298 & 0.083 & 0.208 & 0.340 \\
0.136 & 0.262 & 0.417 & 0.312 & 0.386 & 0.386 & 0.094 & 0.075 & 0.449
\end{array}\right] \\
& \bar{P}_{n}=\left[\begin{array}{lllllllll}
0.413 & 0.205 & 0.139 & 0.176 & 0.075 & 0.075 & 0.457 & 0.409 & 0.089 \\
0.280 & 0.233 & 0.157 & 0.226 & 0.235 & 0.235 & 0.365 & 0.302 & 0.119 \\
0.183 & 0.301 & 0.278 & 0.291 & 0.302 & 0.302 & 0.087 & 0.235 & 0.354 \\
0.138 & 0.265 & 0.447 & 0.330 & 0.409 & 0.409 & 0.099 & 0.075 & 0.449
\end{array}\right] \\
& \bar{P}_{u}=\left[\begin{array}{lllllllll}
0.413 & 0.205 & 0.141 & 0.184 & 0.076 & 0.076 & 0.468 & 0.415 & 0.090 \\
0.286 & 0.238 & 0.163 & 0.226 & 0.238 & 0.238 & 0.365 & 0.302 & 0.123 \\
0.192 & 0.323 & 0.285 & 0.297 & 0.302 & 0.302 & 0.087 & 0.238 & 0.354 \\
0.140 & 0.277 & 0.447 & 0.343 & 0.415 & 0.415 & 0.102 & 0.076 & 0.458
\end{array}\right]
\end{aligned}
$$

All considered fuzzy matrices are consistent, since their consistency ratio is $C R<0.10$.

Vectors of global priorities of alternatives $g_{l}, g_{m}$, $g_{n}$ and $g_{u}$ according to the Eqn (28) are shown in Table 4 . The components of these vectors for each alternative $A_{i}$ determine trapezoidal-shaped fuzzy numbers $\tilde{g}_{i}=\left(g_{i, l}, g_{i, m}, \tilde{g}_{i, n}, g_{i, u}\right)(i=1,2,3,4)$. For these fuzzy numbers are calculated the generalized fuzzy means (expected values) $g_{e, i}$, generalized standard deviations $\sigma_{i}$ and coefficients of variations $V_{i}$ for alternatives $A_{i}(i=1,2,3,4)$ using the Eqns (22), (23), (24) and distance to the centroid point and reduced expected value by

Table 4. Global priorities of alternatives as trapezoidal fuzzy numbers

\begin{tabular}{ccccc}
\hline Alternative $i$ & $g_{i, l}$ & $g_{i, m}$ & $g_{i, n}$ & $g_{i, u}$ \\
\hline Alternative 1 & 0.1650 & 0.1773 & 0.2097 & 0.2186 \\
Alternative 2 & 0.1872 & 0.2001 & 0.2308 & 0.2394 \\
Alternative 3 & 0.2224 & 0.2393 & 0.2793 & 0.2915 \\
Alternative 4 & 0.2830 & 0.3044 & 0.3343 & 0.3467 \\
\hline
\end{tabular}

Eqns (26) and (27) respectively. Ranking of alternatives was performed based on obtained values and the results are shown in the Tables 5,6 and 7. The global priorities of alternatives obtained using proposed method are graphically presented in Figure 4.

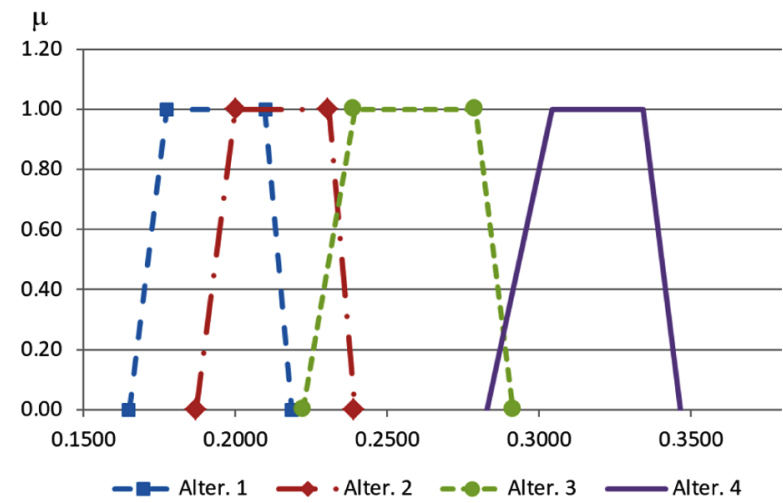

Fig. 4. Global priorities of alternatives presented as trapezoidal fuzzy numbers

Table 5. Ranking of alternatives according to $g_{e, i}$ and $C V_{i}$ for the uniform distribution

\begin{tabular}{cccccc}
\hline $\begin{array}{c}\text { Rank } \\
i\end{array}$ & $\begin{array}{c}\text { According to mean } \\
\text { value } g_{e, i}\end{array}$ & $\begin{array}{c}\text { Mean value } \\
g_{e, i}\end{array}$ & $\begin{array}{c}\text { According to } \\
C V_{i}\end{array}$ & $\begin{array}{c}\text { Coefficient of var. } \\
C V_{i}(\%)\end{array}$ & $\begin{array}{c}\text { Standard deviat. } \\
\sigma_{i}\end{array}$ \\
\hline 1 & Alternative 4 & 0.3168 & Alternative 4 & 4.5523 & 0.0144 \\
2 & Alternative 3 & 0.2580 & Alternative 2 & 5.7789 & 0.0124 \\
3 & Alternative 2 & 0.2143 & Alternative 3 & 6.3189 & 0.0163 \\
4 & Alternative 1 & 0.1926 & Alternative 1 & 6.6391 & 0.0128 \\
\hline
\end{tabular}


Table 6. Ranking of alternatives according to reduced expected values $g_{e r}$ for uniform distribution, $\beta=1$

\begin{tabular}{ccc}
\hline Rank & Alternative & Reduced expect. value \\
$i$ & $A_{i}$ & $g_{e r, i}$ \\
\hline 1 & Alternative 4 & 0.3024 \\
2 & Alternative 3 & 0.2417 \\
3 & Alternative 2 & 0.2019 \\
4 & Alternative 1 & 0.1798 \\
\hline
\end{tabular}

Table 7. Ranking of alternatives according to the distance $R\left(\tilde{g}_{i}\right)$ of the original point to the centroid point

\begin{tabular}{ccccc}
\hline $\begin{array}{c}\text { Rank } \\
i\end{array}$ & $\begin{array}{c}\text { Alternative } \\
A_{i}\end{array}$ & $\begin{array}{c}\text { Component } \\
g_{c, i}\end{array}$ & $\begin{array}{c}\text { Component } \\
y_{c, i}\end{array}$ & $\begin{array}{c}\text { Distance } \\
R\left(\tilde{g}_{i}\right)\end{array}$ \\
\hline 1 & Alternative 4 & 0.3168 & 0.5012 & 0.5929 \\
2 & Alternative 3 & 0.2580 & 0.5008 & 0.5633 \\
3 & Alternative 2 & 0.2143 & 0.5008 & 0.5447 \\
4 & Alternative 1 & 0.1926 & 0.5007 & 0.5365 \\
\hline
\end{tabular}

Presented problem could have been modelled using a more complex hierarchy structure that contains three levels: criteria, subcriteria and alternatives. The four main criteria would be: economical, technical-technological, environmental and socially political. Economic criteria would be divided into investments and the cost of exploitation. Technical-technological would be broken into safety in the operation of facilities and duration of construction. Environmental would be divided into the influence of environment on future facilities, the impact of the planned facilities on the environment and visual and aesthetic effects. Socially political could contain the influence of sociological factors on the planned facilities and the impact of socio-political community on the planned facilities. All alternatives would be connected with all subcriteria. Proposed procedure could be applied on this more complex hierarchy structure.

\section{Discussion}

According to the obtained results, it may be concluded that for all used ranking rules the alternative $\mathrm{A}_{4}$ has an advantage over the other alternatives, and alternatives are ranked in the sequence $A_{4}>A_{3}>A_{2}>A_{1}$. When alternatives are ranked according to the coefficient of variation the sequence is $A_{4}>A_{2}>A_{3}>A_{1}$. The resulting difference in the ranking of alternatives according to coefficient of variation reflects the fact that the ranking by this coefficient is not always reliable. Therefore, in this paper is proposed more reliable ranking by corrected expected value that contains the standard deviation. Ranking of alternatives according by proposed formula is also $A_{4}>A_{3}$ $>A_{2}>A_{1}$.

Alternative $A_{4}$ is significantly better ranked than the other alternatives, so the alternative $A_{4}$ has been accepted by the investor for the realization.

To confirm results obtained by proposed method this problem was also solved by using next procedures: Csutora and Buckley (2001) fuzzy AHP procedure, AHP method with defuzzified crisp values of the input fuzzy numbers and AHP with crisp numbers. Defuzzification of input fuzzy numbers was performed in two ways, by using following formulas:

$$
\begin{aligned}
& a=\left(a_{l}+a_{m}+a_{n}+a_{u}\right) / 4 ; \\
& a=\left(a_{l}+2 a_{m}+2 a_{n}+a_{u}\right) / 6,
\end{aligned}
$$

where $a$ is defuzzified crisp number.

Obtained global priorities of alternatives according to these four procedures are presented in Table 8 .

From Table 8 may be concluded that values of global priorities for ranking alternatives that are obtained by proposed procedure are close to the values calculated by applying other mentioned procedures. Also, ranks of the alternatives are the same. This proves the correctness and accuracy of the proposed procedure.

The similar result of ranking of alternatives for this problem is also obtained by the fuzzy TOPSIS method in the paper (Prascevic Z., Prascevic N. 2013) and obtained the same ranking sequence of alternatives.

Based on presented study following can be emphasized:

1. In comparison with other MCDM methods proposed method has several advantages. Decision making during project realization is connected with many qualitative and quantitative factors. Quantitative factors such as cost, profit, risk, time of project realization and so on, cannot be accurately estimated in advance for many reasons. On the other hand, there are qualitative factors, such as social, environmental, functional, technical and technological, that can be expressed only by linguistic values. Therefore, in the process of decision making in construction management it is more appropriate to apply methods based on the theory of fuzzy sets and fuzzy logics than methods based on crisp numbers.

2. Fuzzy AHP method is very applicable, since it resembles human reasoning. The method is based on

Table 8. Global priorities according to proposed procedure and other procedures

\begin{tabular}{ccccccc}
\hline $\begin{array}{c}\text { Rank } \\
i\end{array}$ & $\begin{array}{c}\text { Alternative } \\
A_{i}\end{array}$ & $\begin{array}{c}\text { Proposed } \\
\text { method }\end{array}$ & $\begin{array}{c}\text { Csutora and } \\
\text { Buckley }\end{array}$ & $\begin{array}{c}\text { Defuzzification } \\
\text { (first way) }\end{array}$ & $\begin{array}{c}\text { Defuzzification } \\
\text { (second way) }\end{array}$ & $\begin{array}{c}\text { AHP with crisp } \\
\text { numbers }\end{array}$ \\
\hline 1 & Alternative 4 & 0.3168 & 0.3147 & 0.3214 & 0.3219 & 0.3117 \\
2 & Alternative 3 & 0.2580 & 0.2572 & 0.2637 & 0.2634 & 0.2597 \\
3 & Alternative 2 & 0.2143 & 0.2134 & 0.2181 & 0.2181 & 0.2240 \\
4 & Alternative 1 & 0.1926 & 0.1919 & 0.1969 & 0.1966 & 0.2046 \\
\hline
\end{tabular}


assessment of comparisons between different factors. In many situations, it is easier for experts to evaluate comparisons between factors then to determinate their values particularly.

3. Trapezoidal fuzzy numbers are more general than triangular one. Application of trapezoidal fuzzy numbers enables to express factors and their comparisons in more realistic way. Unlike crisp numbers, where values of factors are evaluated by singular value, in case of trapezoidal fuzzy AHP values are expressed by the range of values which extends the range of comparison matrices.

4. Unlike to proposed methods by some other authors, who at the beginning of the procedure defuzzify fuzzy numbers and get results as crisp numbers, the method proposed in this paper does not include defuzzification at the beginning, so the obtained global priorities are also fuzzy numbers which better reflects reality.

\section{Conclusions}

The methods of multiple criteria decision making (MCDM) play a key role in construction project management (CPM) and construction industry (CI). One of them is the Analytic hierarchy process (AHP). The main advantage of this method is that factors included in the comparison matrices of the criteria and alternatives have not been presented by exact numerical values. It is enough to correctly assess their values of comparisons. This is very useful in the first phases of the project, during preparation of feasibility studies, when many important data are not exactly known yet. Since, in the practice, these comparisons values are imprecise and usually are assessed by the experts on the basis of their experience and inexact data, it is recommended to express comparison values by the fuzzy numbers and solve the problem by the fuzzy AHP. This procedure enables to obtain ranking of alternatives reasonable correct, especially when the data are imprecise.

Main contribution of this paper is proposal of the new method for fuzzy AHP, that is based on eigenvalue and eigenvector approach which is different from proposals of the other authors. The method is simple and very suitable for development of a corresponding computer program and gives results of requested accuracy, which is confirmed by comparisons with results of some other proposals. The proposed method is developed for trapezoidal fuzzy numbers, but can be also used for triangular ones.

The main differences and advantages of this proposal in comparison with other ones are following. First, solution of fuzzy eigenvalue problem is based on determination of expected values of fuzzy numbers and their products. Fuzzy eigenvalue problem with trapezoidal fuzzy numbers is transformed into four auxiliary crisp eigenvalue problems. Using a standard computer subroutine characteristic fuzzy eigenvalues and eigenvectors that correspond to the considered fuzzy eigenvalue problem are obtained. Second, characteristic fuzzy priority vectors (weights) for the alternatives and criteria are determined by linear programming. Third, ranking of alternatives, expressed by the trapezoidal fuzzy numbers, was made by formula proposed by the authors. This formula is based on ranking fuzzy numbers by reduced generalized fuzzy mean, since ranking by the coefficient of variation is not always reliable, as it is shown in the case study.

For application of this method of MCDM in practice, it is necessary to form a capable team made up of experts of appropriate specialization, define the goals, methodology and hierarchical model. The experts need corresponding documentation and data base for good assessments of the input data. The validity of the obtained results for decision making depends on the quality of the expert assessments and chosen model.

The proposed method can be applied for different areas of construction project management to solve large scale decision making problems using personal computers. Practical contributions of this method are based on its simplicity, clarity, accuracy and applicability in decision making. The method and the computer program, developed by the authors, have been used for decision making in realization of several construction projects, such as: choice of the optimal railway route, optimal choice of structural system of industrial halls, choice of the optimal gas line crossing over the river Danube etc.

In our further research in this field we will deal with:

1. Fuzzy AHP with other membership functions ("bell", "S", "Pi", "Gauss") of fuzzy numbers.

2. Problems of group decision making in construction industry (establishing of expert team from different specialities, data collecting and processing).

3. Fuzzy analytical network process (FANP).

4. Integration of fuzzy AHP with other method of MCDM.

These accomplishments will be applied to the problems in the construction project management and industry.

\section{References}

Al-Harbi, K. M. 2001. Application of the AHP in project management, International Journal of Project Management 19: 19-27. https://doi.org/10.1016/S0263-7863(99)00038-1

Antuchevičiene, J.; Zavadskas, E. K.; Zakarevičius, A. 2010. Multiple criteria construction management decisions considering relations between criteria, Technological and Economic Development of Economy 16(1): 109-125. https://doi.org/10.3846/tede.2010.07

Buckley, J. J. 1985. Fuzzy hierarchical analysis, Fuzzy Sets and Systems 17: 233-247. https://doi.org/10.1016/0165-0114(85)90090-9

Buckley, J. J.; Feuring, T.; Hayashi, Y. 2001. Fuzzy hierarchical analysis revisited, European Journal of Operational Research 129: 48-64. https://doi.org/10.1016/S0377-2217(99)00405-1

Chang, D. Y. 1992. Extent analysis and synthetic decision, optimization techniques and applications. Vol. 1. Singapore: World Scientific.

Chang, D. Y. 1996. Application of the extent analysis method on fuzzy AHP, European Journal of Operational Research 95: 649-655. https://doi.org/10.1016/0377-2217(95)00300-2 
Cheng, C. H. 1998. A new approach for ranking fuzzy numbers by distance method, Fuzzy Sets and Systems 95: 307-317. https://doi.org/10.1016/S0165-0114(96)00272-2

Cheung, S. O.; Lam, T. I.; Leung, M. Y.; Wan, Y. W. 2001. An analytical hierarchy process based procurement selection, Construction Management and Economy 19: 427-437. https://doi.org/10.1080/014461901300132401

Csutora, R.; Buckley, J. J. 2001. Fuzzy hierarchical analysis: the Lambda-Max method, Fuzzy Sets and Systems 120: 181-195. https://doi.org/10.1016/S0165-0114(99)00155-4

del Cano, A.; de la Cruz, M. P.; Gomez, D.; Perez, M. 2016. Fuzzy method for analysing uncertainty in the sustainable design of concrete structures, Journal of Civil Engineering and Management 22(7): 924-935. https://doi.org/10.3846/13923730.2014.928361

Dubois, D.; Prade, H. 1987. The mean value of fuzzy numbers, Fuzzy Sets and Systems 24: 279-300. https://doi.org/10.1016/0165-0114(87)90028-5

Erdogan, S. A.; Saparauskas, J.; Turskis, Z. 2017. Decision making in construction management: AHP and Expert choice approach, Procedia Engineering 172: 270-276. https://doi.org/10.1016/j.proeng.2017.02.111

Ertugrul, I.; Karakasoglu, N. 2008. Comparison of fuzzy AHP and fuzzy TOPSIS methods for facility location selection, International Journal of Advanced Manufacture Technology 39: 783-795. https://doi.org/10.1007/s00170-007-1249-8

Hastak, M. 1998. Advanced automation or conventional construction process, Automation in Construction 7: 299-314. https://doi.org/10.1016/S0926-5805(98)00047-8

Jaskowski, P.; Biruk, S.; Bucon, R. 2010. Assessing contractor selection criteria weights with fuzzy AHP method application in group decision environment, Automation in Construction 19: 120-126. https://doi.org/10.1016/j.autcon.2009.12.014

Kusumawardani, R. P.; Agintiara, M. 2015. Application of fuzzy AHP - TOPSIS methods for decision making in human resource manager selection process, Procedia Computer Science 72: 638-646. https://doi.org/10.1016/j.procs.2015.12.173

Kwiesielewicz, M. 1998. A note on the fuzzy extension of Saaty's priority theory, Fuzzy Sets and Systems 95: 161172. https://doi.org/10.1016/S0165-0114(96)00329-6

Lee, E. S.; Li, R. L. 1988. Comparison of fuzzy numbers based on the probability measure of fuzzy events, Computers and Mathematics with Applications 15: 887-896. https://doi.org/10.1016/0898-1221(88)90124-1

Mahmoodzadeh, S.; Shahrabi, J.; Pariazar, M.; Zaeri, M. S. 2007. Project selection by using fuzzy AHP and TOPSIS technique, International Journal of Humanities and Social Science 1(3): 135-141.

Pan, N. F. 2008. Fuzzy AHP approach for selecting the suitable bridge construction method, Automation in Construction 17: 958-965. https://doi.org/10.1016/j.autcon.2008.03.005

Polat, G. 2016. Subcontractor selection using the integration of the AHP and PROMETHEE methods, Journal of Civil Engineering and Management 22(8): 1042-1054. https://doi.org/10.3846/13923730.2014.948910

Prascevic, Z.; Prascevic, N. 2013. One modification of fuzzy TOPSIS method, Journal of Modeling in Management 8: 81-102. https://doi.org/10.1108/17465661311311996
Prascevic, N.; Prascevic, Z. 2016. Application of fuzzy AHP method on eigenvalues for decision making in construction industry, Technical Gazette 23(1): 57-64.

Ruoning, X.; Xiaoyan, Z. 1992. Extensions of the analytic hierarchy process in fuzzy environment, Fuzzy Sets and Systems 52: 251-257. https://doi.org/10.1016/0165-0114(92)90236-W

Saaty, T. L. 1977. Scaling method for priorities in hierarchical structures, Journal of Mathematical Psychology 15(3): 234-281.

https://doi.org/10.1016/0022-2496(77)90033-5

Saaty, T. L. 1980. The analytic hierarchy process. New York: McGraw-Hill.

Saaty, T. L. 1990. How to make a decision: Analytic hierarchy process, European Journal of Operational Research 48: 9-26. https://doi.org/10.1016/0377-2217(90)90057-I

Salehi, M.; Tavakkoli-Moghaddam, R. 2008. Project selection by using a fuzzy TOPSIS technique, International Journal of Mechanical, Aerospace, Industrial, Mechatronic and Manufacturing Engineering 40: 85-90.

Shapira, A.; Goldenberg, M. 2005. AHP - based equipment selection model for construction projects, Journal of Construction Engineering and Management 131: 1263-1273. https://doi.org/10.1061/(ASCE)07339364(2005)131:12(1263)

Skibniewski, M. J.; Chao, L. C. 1992. Evaluation of advanced construction technology with AHP method, Journal of Construction Engineering and Management 118: 577-593. https://doi.org/10.1061/(ASCE)07339364(1992)118:3(577)

Taylan, O.; Bafail, A. O.; Abdulaal, R. M. S.; Kabli, M. R. 2014. Construction projects selection and risk assessment by fuzzy AHP and fuzzy TOPSIS methodologies, Applied Soft Computing 17: 105-116. https://doi.org/10.1016/j.asoc.2014.01.003

Torfi, F.; Farahani, R. Z.; Rezapour, S. 2010. Fuzzy AHP to determine the relative weights of evaluation criteria and fuzzy TOPSIS to rank alternatives, Applied Soft Computing 10: 520-528. https://doi.org/10.1016/j.asoc.2009.08.021

Vaidya, O. S.; Kumar, S. 2006. Analytic hierarchy process: An overview of applications, European Journal of Operational Research 169: 1-29. https://doi.org/10.1016/j.ejor.2004.04.028

van Laarhoven, P. J. M.; Pedrycz, W. 1983. A fuzzy extension of Saaty's priority theory, Fuzzy Sets and Systems 11: 229-241.

https://doi.org/10.1016/S0165-0114(83)80082-7

Walker, A. 1989. Project management in construction. $2^{\text {nd }}$ ed. BSP Professional Books.

Zadeh, L. A. 1968. Probability measures of fuzzy events, Journal of Mathematical Analysis and Applications 23: 421427. https://doi.org/10.1016/0022-247X(68)90078-4

Zavadskas, E. K.; Turskis, Z.; Tamošaitiene, J. 2010. Risk assessment of construction projects, Journal of Civil Engineering and Management 16(1): 33-46. https://doi.org/10.3846/jcem.2010.03

Zeng, J.; Smith, J. N. 2007. Application of a fuzzy based decision making methodology to construction project risk assessment, International Journal of Project Management 25: 589-600. https://doi.org/10.1016/j.ijproman.2007.02.006 


\section{Appendix}

The trapezoidal fuzzy number $\widetilde{a}$ is usually described by four characteristic real numbers $a_{l}, a_{m}, a_{n}$ and $a_{u}$ $\widetilde{a}=\left(a_{l}, a_{m}, a_{n}, a_{u}\right) \quad 0 \leq a_{l} \leq a_{m} \leq a_{n} \leq a_{u}$.

A membership function of the trapezoidal fuzzy number $\widetilde{a}$ is:

$$
\mu_{\widetilde{a}}(x)=\left\{\begin{array}{l}
\frac{x-a_{l}}{a_{m}-a_{l}} \text { for } a_{l} \leq x \leq a_{m}, \\
1 \text { for } x_{m} \leq x \leq x_{n}, \\
\frac{a_{u}-x}{a_{u}-a_{n}} \text { for } a_{n} \leq x \leq a_{u}, \\
0 \text { otherwise. }
\end{array}\right.
$$

If for the trapezoidal fuzzy number is $a_{n}=a_{m}$, it becomes the triangular one, which might be written $\tilde{a}=\left(a_{l}, a_{m}, a_{m}, a_{u}\right) \quad$ or $\quad \tilde{a}=\left(a_{l}, a_{m}, a_{u}\right)$, $0<a_{l} \leq a_{m} \leq a_{u}$.

Fuzzy number $\widetilde{a}$ at level $\alpha$, or $\alpha$-cut, may be presented in the form $\tilde{a}(\alpha)=\left[a_{L}(\alpha), a_{R}(\alpha)\right], 0<\alpha \leq 1$, where for the trapezoidal fuzzy number;

$$
\begin{aligned}
& a_{L}(\alpha)=a_{l}+\left(a_{m}-a_{l}\right) \alpha ; \\
& a_{R}(\alpha)=a_{u}-\left(a_{u}-a_{n}\right) \alpha .
\end{aligned}
$$

Reciprocal fuzzy number $\tilde{a}^{-1}$ to $\tilde{a}$ is for $a_{l}>0$, $\tilde{a}^{-1}(\alpha)=\left[a_{L}^{-1}(\alpha), a_{R}^{-1}(\alpha)\right]$.

These reciprocal fuzzy numbers $\widetilde{a}^{-1}(\alpha) \quad(0<\alpha \leq 1)$ are not exactly trapezoidal ones, and they are called trapezoidal - shaped fuzzy numbers (Buckley 1985). Due to simplicity of the analysis and calculations, these reciprocal fuzzy numbers are approximated by trapezoidal ones and represented by the characteristic values (Buckley 1985; Buckley et al. 2001; van Laarhoven, Pedrycz 1983)

$\tilde{a}^{-1}=\left(a_{l}, a_{m}, a_{n}, a_{u}\right)^{-1}=\left(a_{u}^{-1}, a_{n}^{-1}, a_{m}^{-1}, a_{l}^{-1}\right), \quad a_{l}>0$.
Element $\tilde{f}_{j i}$ of fuzzy comparison matrix $\widetilde{F}$ for the trapezoidal fuzzy numbers is:

$$
\begin{gathered}
\tilde{f}_{i j}=\left(f_{i j, l}, f_{i j, m}, f_{i j, n}, f_{i j, u}\right), \tilde{f}_{i i}=(1,1,1,1), f_{i j, l}>0, \\
i, j=1,2, \ldots, k,
\end{gathered}
$$

while reciprocal elements $\tilde{f}_{j i}$ is:

$$
\tilde{f}_{j i}=\tilde{f}_{i j}^{-1}=\left(f_{i j, u}^{-1}, f_{i j, n}^{-1}, f_{i j, m}^{-1}, f_{i j, l}^{-1}\right), \quad i, j=1,2, \ldots, n \text {. }
$$

As Buckley et al. (1985) emphasize, the fuzzy positive reciprocal matrix $\widetilde{F}$ usually is not perfectly, but only reasonable consistent, for which is valid $\tilde{f}_{i k} \otimes \tilde{f}_{k j} \approx \tilde{f}_{i j}, i, j, k=1,2, \ldots, n$ where the sign $\otimes$ denotes the fuzzy product.

The expected value of a fuzzy number $\widetilde{p}$ is (Dubois, Prade 1987):

$$
E V(\tilde{p})=0.5 \int_{0}^{1}\left[p_{L}(\alpha)+p_{R}(\alpha)\right] d \alpha .
$$

Substituting $p_{L}(\alpha)$ and $p_{R}(\alpha)$ by expressions (A1) after integration for trapezoidal fuzzy number obtains:

$$
E V(\tilde{p})=\left(p_{l}+p_{m}+p_{n}+p_{u}\right) / 4 .
$$

According to (A1) for two positive fuzzy numbers $\widetilde{p}$ and $\widetilde{q}$ is:

$$
\tilde{p}(\alpha) \otimes \tilde{q}(\alpha)=\left[p_{L}(\alpha) q_{L}(\alpha), p_{R}(\alpha) q_{R}(\alpha)\right],
$$

The expected value of the product of two trapezoidal fuzzy numbers can be obtained by expressing $p_{L}(\alpha)$ and $p_{R}(\alpha)$ in the form Eqn (4) by $p_{l}, p_{m}, p_{n}, p_{u}$ and $q_{d}(\alpha)$ and $q_{g}(\alpha)$ by $q_{l}, q_{m}, q_{n}, q_{u}$, where $p_{l}>0$, $q_{l}>0$ :

$$
\begin{aligned}
E V(\tilde{p} \otimes \tilde{q})= & \frac{1}{12}\left[\left(2 p_{l}+p_{m}\right) q_{l}+\left(p_{l}+2 p_{m}\right) q_{m}+\right. \\
& \left.\left(2 p_{n}+p_{u}\right) q_{n}+\left(p_{n}+2 p_{u}\right) q_{u}\right] .
\end{aligned}
$$

Natasa PRASCEVIC. An Assistant professor at the University of Belgrade, Faculty of Civil Engineering, Serbia, where she also serves as the Vice dean. She conducted her PhD studies at University of Belgrade. Her main areas of research interest include IT in construction, information systems, operational research, soft computing. She has been involved in several research projects sponsored by Ministry of science and technology progress in Serbia. She published several books and more than 30 papers in national and international journals and proceedings.

Zivojin PRASCEVIC. A Full Tenured Professor at the University of Belgrade, Faculty of Civil Engineering, Serbia. He has been Professor of Construction management and technology, Operational research at the University of Belgrade, Faculty of Civil Engineering, University of Montenegro, Podgorica and Visiting Professor at several other universities in former Yugoslavia. He is ordinary member of the Academy of Engineering Sciences of Serbia and secretary of its Division of Civil Engineering Sciences. He has been the dean of the Civil Engineering Faculty and Head of the Department of Construction Management and Technology. His scientific, professional and design work is related to the construction management, operational research, structural engineering and optimization. 